\section{La distribución de lo inteligible y lo sensible hoy}

Alejandra Niedermaier *

\begin{abstract}
Resumen: La emergencia de la visualidad y las tecnologías contemporáneas solicitan una reflexión sobre su impacto en la constitución de la subjetividad y en el desarrollo de las prácticas discursivas con el objeto de dilucidar los distintos aspectos que, hoy, hacen a la sensibilidad, el pensamiento y la creatividad.
\end{abstract}

Palabras clave: didáctica - inteligiblidad - subjetividad - tecnología - visualidad.

[Resúmenes en inglés y portugués en la página 51]

(*) Fotógrafa, docente e investigadora. Maestría en Lenguajes Artísticos Combinados (IUNA, tesis en curso). Se desempeña como docente en la Universidad de Palermo y en el Posgrado de Lenguajes Artísticos Combinados del IUNA. Coordinadora de contenidos de la carrera de la Escuela de Fotografía Motivarte.

Contemporáneo es aquel que percibe la oscuridad de su tiempo como algo que le incumbe y no cesa de interpelarlo, algo que, más que cualquier luz, se dirige directa y singularmente a él. Contemporáneo es aquel que recibe en pleno rostro el haz de tiniebla que proviene de su tiempo (Agamben, 2011, p. 22).

Esta frase de Agamben junto a la siguiente de Walter Benjamin:

Dentro de largos períodos históricos, junto con el modo de existencia de los colectivos humanos, se transforma también la manera de su percepción. El modo en que se organiza la percepción -el medio en que ella acontece- está condicionado no sólo natural sino históricamente (Benjamin, 1973, p. 153).

son el punto de partida de estas consideraciones. Justamente, la iconósfera y la tecnósfera contemporáneas solicitan una reflexión sobre su impacto en la constitución de la subjetividad y en el desarrollo de las prácticas discursivas para dilucidar los distintos aspectos que, hoy, hacen a la sensibilidad, el pensamiento y la creatividad. El hombre se ha configurado con cierta plasticidad, cierta versatilidad a lo largo de su historia y gracias a esta característica resulta permeable a una amplia gama de posibilidades que modelan su subjetividad. 
En virtud de que mi área de acción y exploración se despliega dentro del campo de lo visual el presente escrito tratará de comprender los aspectos relativos a ese ámbito. En este sentido, se debe caracterizar primero el espacio plástico que nos circunda. En él se despliega el concepto de "visualidad"1 como sinónimo de textualidad, como procedimiento que integra y describe la cultura visual contemporánea. La visualidad comprende, entonces, el desciframiento, la decodificación y la interpretación de la experiencia visual a través de variables propias, algunas heredadas del modelo textual y otras proporcionadas por sus indicadores específicos. De este modo, estamos inmersos en una iconósfera ya que las imágenes determinan el modo de percibir, interpretar y pensar el mundo. La comunicación visual es, por tanto, una construcción de sentido interactiva y cultural.

Con la intención de profundizar en la caracterización y reflexión se analizará la incidencia que la tecnósfera despliega sobre esta atmósfera plagada de imágenes. Ella alude a las diferentes técnicas y tecnologías que se utilizan cotidianamente en las diferentes disciplinas. Por otra parte, resulta relevante reconocer las rupturas que la emergencia de la tecnología instaura porque cada vez que muta la tecnología, tanto las prácticas sociales y culturales como los aspectos, simbólicos y cognitivos se modifican.

Asimismo, se trazarán algunas consideraciones sobre los aspectos didácticos. La intencionalidad de este escrito no es realizar previsiones futuras en el entendimiento de que la escritura del acontecer está absolutamente abierta. Simplemente, se trata de reflexionar acerca de posibles procesos de singularización que integran diferentes significantes existenciales y que sirvan como herramientas para la creatividad, para forjar nuevas relaciones interpersonales y sociales y que, a su vez, tiendan a evitar la uniformidad de pensamientos y comportamientos.

\section{Visualidad}

En el recorrido sobre los distintos análisis que ambas características contemporáneas solicitan, se observa que los estudios visuales examinan el universo de las imágenes cualesquiera sea su procedencia y circulación (arte, publicidad, diseño, moda, medios audiovisuales y masivos y las posibilidades que las tecnologías digitales proporcionan). De este modo, reconocen a la cultura de la imagen como parte integrante de la cultura posmoderna y de la globalización capitalista comprendiendo que las mismas no pertenecen a un espacio cultural único. Estos estudios buscan pues aportar una respuesta al auge de la visualidad desde distintas disciplinas de análisis: historia del arte, estética, antropología, psicología, semiótica, literatura, comunicación. El historiador de arte W.J.T. Mitchell sostiene que el análisis de la imagen ya no debe ser realizado a partir de parámetros como la mimesis, la representación sino a partir de una interacción de características tales como discurso, presentación, instituciones, tomando en consideración además, la figura del receptor. ${ }^{2}$ Desde esta perspectiva, Keith Moxey manifiesta: "los estudios visuales están interesados en cómo las imágenes son prácticas culturales cuya importancia delata los valores de quienes las crearon, manipularon y consumieron" (Guasch Ana María, p. 16). Jonathan Crary indica, en sus estudios, que ya la cámara oscura conformaba un nuevo modelo de subjetividad que contribuía a la representación del espacio profundo. Justamente, la aparición de la perspectiva implicaba tal como lo considera el historiador de arte Erwin Panofsky 
una forma de simbolizar el espacio cumpliendo así con el deseo de representación de la mirada renacentista. A propósito, Vilém Flusser caracteriza como imágenes prehistóricas a las tradicionales y a las técnicas (en las que ya mediaba el texto como resultado de una abstracción ) como poshistóricas.

Las imágenes se sitúan pues en los pliegues de lo simbólico y lo real, de lo conceptual y lo existente, de lo mágico y lo existencial. A pesar de que la capacidad movilizadora de las mismas se registra desde la antigüedad se puede afirmar que en la contemporaneidad esta facultad se ha ido incrementando. A propósito, el analista político italiano Giovanni Sartori distingue al "homo sapiens" del "homo videns" ( Sartori, 1998) al sostener que ha finalizado la era del Homo Sapiens, en la que se creía en un ser humano capaz de saber, reflexionar, pensar y analizar el mundo. En su lugar, se encuentra el Homo Videns, un ser que sólo es capaz de observar las imágenes del mundo y digerirlas con formatos prefijados. El homo videns consume imágenes y, su carácter de espectador, reduce su capacidad simbólica y de abstracción. El ya mencionado W.J.T. Mitchell se refiere a este giro como "del mundo como texto al mundo como imagen".

El hombre contemporáneo se encuentra inmerso en una formación socio-cultural derivada de diferentes pantallas e imágenes en donde, por ejemplo, la pantalla de la televisión ejerce un rol de autoridad para identificar y legitimar pares binarios tales como lo bueno/lo malo, lo nuevo/ lo antiguo, lo importante/lo intrascendente. Instaura pues el régimen de verdad: si aparece en pantalla su existencia es real. Por régimen de verdad se comprende lo establecido por Michel Foucault:

Por "verdad" (debe) entender(se) un conjunto de procedimientos reglamentados por la producción, la ley, la repartición, la puesta en circulación, y el funcionamiento de los enunciados. La "verdad" está ligada circularmente a los sistemas de poder que la producen y la mantienen, $\mathrm{y}$ a los efectos de poder que induce y que la acompañan (Foucault, 1992, p. 189).

Precisamente, la visualidad puede en ocasiones contener un oxímoron, es decir, unir poéticamente dos conceptos de significado opuesto en una sola expresión. Las palabras "idea" y "video" contienen la misma raíz indoeuropea "id"(vid). Idear y ver implica entonces un enunciador conciente de que está ideando una cadena de significados a mostrar y de su probable polisemia. El escritor y crítico de cine Pascal Bonitzer describe a las emociones como planos de intensidad al sostener: "El cine moderno rompe los planos de emoción, inventa nuevas relaciones entre los planos; despega al cine de las emociones comunes para producir sensaciones nuevas, menos identificables, menos identificatorias" (Bonitzer, 2007, p. 98).

Entonces, idear y mostrar, en tanto conocimiento, en tanto creación de imaginarios, en tanto expresión estética personal resulta, en resumen, un oxímoron que articula lo sensible y lo inteligible. ${ }^{3}$

En suma, para comprender la iconósfera en toda su dimensión -como reflejo simbólico de un imaginario político, social y cultural- se requiere un ejercicio hermenéutico que, mediante los aportes de distintas disciplinas y sin establecer límites entre ellas, permita una lectura paradigmática y sintagmática de la visualidad. 


\section{Los paradigmas de la tecnología}

En primer lugar, resulta absolutamente evidente que el gran impacto de la tecnósfera es la instauración de un modo diferente de articulación entre los procesos simbólicos que constituyen los bienes culturales y afectan los modos de producción y distribución de esos mismos bienes. Los paradigmas de la tecnología refieren a un mundo de relaciones y funciones que coloca entre paréntesis a la subjetividad. Es, en el modo de elaboración de lo objetivo y lo subjetivo, de lo finito a lo infinito donde se manifiestan las repercusiones del cambio de paradigma. Se produce así una desterritorialización de lo corpóreo para una reterritorialización inmaterial. ${ }^{4}$ En tal sentido, el semiólogo Eliseo Verón menciona que la tecnología se encuentra en "una superficie sin inscripciones, donde se mueven formas inciertas como en las planchas del test de Rorschach, superficie sobre la cual la sociedad proyecta sus fantasmas más secretos" (p. 62). Esto pone de relieve su condición de modelo mental ya que implica una forma de gestionar el conocimiento que va desde la posibilidad de desarrollos muy simples a otros verdaderamente complejos. Es por ello que lo que, en términos amplios, se denomina interfaz ${ }^{5}$ plantea consideraciones epistemológicas, psico-sociales, éticas y estéticas. La forma interfaz articula, de algún modo, formas de conocimiento en la cultura contemporánea.

La tecnología contiene una matriz simbólica que construye un imaginario. Por eso, el pensador Félix Guattari menciona que las transformaciones tecnológicas implican una tendencia a la homogeneización de la subjetividad (p.15). Señala, en este mismo sentido, que se catalizan "universos de virtualidad" ( $i b i d$, p.154) cuando aparece un nuevo vocabulario que da cuenta de los distintos procedimientos tecnológicos.

Una de las características que constituye el imaginario es la concepción de lo ilimitado, la promesa de que todo es o será realizable. El doctor en leyes, ciencias y letras, Alvin Toffler ya en 1980 identificaba tres factores asociados a la tecnología que inciden sobre la constitución de la subjetividad. Los denominó: Novedad, Diversidad, Transitoriedad. Se observa pues que la necesidad se encuentra frecuentemente asociada a la novedad comenzando así un círculo que se retroalimenta continuamente al crear, alrededor de la novedad, un imaginario que conduce a convertirse en necesidad. Esto produce un distanciamiento con los objetos de la cultura estableciendo así nuevos modos de relación que demuestran una modalidad mediatizada y una tendencia a la perpetua "rotación". Además, esta mediatización, esta lejanía va construyendo nuevas identidades en las cuales se pueden encontrar fenómenos de extrema individualidad. Si trazamos un paralelo con el impacto que produjeron las primeras proyecciones de "La llegada del tren a la estación" de los hermanos Lumière en 1895 que hizo que los espectadores salieran corriendo de la sala asustados porque tenían la sensación de que el tren se les venía encima -como lenguaje aún no codificado y al que todavía no estaban habituados- podemos observar que en la actualidad, con respecto a la aparición de constantes y novedosos resultados tecnológicos, el valor de impacto es menor. Esto significa que nuestra subjetividad ha naturalizado, en el presente, el vertiginoso paso hacia nuevas modalidades. En tal sentido, Guy Gauthier sostiene: "El triunfo de cualquier código es el de hacerse olvidar como tal, y dar la ilusión de que el mismo está determinado por imperativos 'naturales'” (Gauthier Guy, p. 36).

Por otra parte, aparece un proceso de fragmentación de la sociedad según su accesibilidad a las nuevas tecnologías. Éste instaura nuevas percepciones de pertenencia e inclusión comunitaria. Como consecuencia, aparecen sectores excluidos y una nueva distribución de capacidades y po- 
sibilidades. Resulta insuficiente entonces, creer, por ejemplo, que navegar por la red y conocer la realidad a través de ella es una nueva forma de compromiso ciudadano sin necesidad de asumir nuestra responsabilidad como sujetos actuantes. Por tanto, resulta de vital importancia que la educación superior forme profesionales que se planteen descongelar esta situación que aparece como inmodificable, movilizando las estructuras que se han instaurado hasta el presente. Por su parte, el filósofo Jesús Martín-Barbero caracteriza que

la revolución tecnológica ha dejado de ser una cuestión de medios, para pasar a ser decididamente una cuestión de fines, es porque estamos ante la configuración de un ecosistema comunicativo conformado no sólo por nuevas máquinas o medios, sino por nuevos lenguajes, sensibilidades, saberes y escrituras, por la hegemonía de la experiencia audiovisual sobre la tipográfica, y por la reintegración de la imagen al campo de la producción del conocimiento (MartínBarbero, 2002)

La posibilidad de una interactividad también influye en la subjetividad ya que desplaza la atención del "objeto" a su desmaterialización, es decir, a un estadío conformado por un organismo vivo dirigido al contexto y al receptor, al que se le otorga la posibilidad de una manipulación y una variación hacia su propia relatividad. Esto lo convierte en un operador al que le es permitido jugar con un mundo externo y un mundo interno. En tal sentido produce una liberación de las instancias de realidad y de tiempo/espacio ${ }^{6}$ convocando así a análisis sobre el desplazamiento de la veracidad a la verosimilitud y al simulacro ya descriptos por Jean Baudrillard.7 Vilem Flüsser indica que el hombre ya no es un homo faber (trabajador) sino un homo ludens (jugador) que le otorga características de juguete a los distintos aparatos involucrados (de ahí las bromas sobre el "chiche nuevo"). Se da aquí una situación de inmersión en el aparato. Estos ya no son considerados instrumentos como en la época del artesano pre-industrial y tampoco máquinas como en la industrial.

\section{Lazos entre Visualidad y Tecnología}

Ambas particularidades someramente analizadas presentan una estructura rizomática en el sentido que cualquiera de sus puntos puede y está conectado con el otro y se convierten así en un sistema dúctil y mutante. Además, hasta la imagen más arcaica ha requerido de una tecnología de producción y/o de recepción que conlleva la elaboración de útiles y de un saber, es decir, de una tekné.

Uno de los fenómenos que se pueden observar en la actualidad es la proliferación de imágenes resultantes de técnicas digitales, de usuarios de cámaras de formato compacto y teléfonos celulares que borran los lindes entre lo público y lo privado y originan un deseo íntimo de tornar pública la esfera privada. Así se publican imágenes en Facebook y otras redes sociales. Es por ello que estas "imágenes" cumplen con el deseo de visibilidad constante e implican un nuevo tipo de yo. Un modo de exponer la subjetividad y, también, un modo de multiplicarla y, de a ratos, jugar a metamorfosearla.

El lazo que se establece entre Visualidad y redes sociales por ejemplo, posee un efecto "consa- 
gratorio" similar al que describe Giorgio Agamben en su libro Signatura rerum con respecto a la proximidad entre sacramentos y magia en la práctica del bautismo de las imágenes. El bautismo ritual aumentaba la eficacia de éstas y le otorgaba fines mágicos. Acaso, ¿la colocación de ellas en las redes sociales no implica la ilusión de que operen de un modo consagratorio y mágico? Por otra parte, las redes sociales y su sobreabundancia de imágenes resultan nuevos espacios de control que se convierten en regímenes de poder y de saber; forman parte así de tecnologías de biopoder tal como lo denominara Foucault.

En esta revisión de lo que acontece en la unión de lo visual con lo tecnológico, es dable examinar también las consecuencias de la pérdida de los grandes relatos. Los grandes relatos otorgaban un sentido colectivo e individual a la vida. En el momento en que entran en crisis el sujeto pierde el anclaje a lo trascendente (ya sea político, cultural o religioso). Esta carencia devino en un sujeto atento a su presente, a su realidad inmediata y a como visibilizarla, especialmente a través de la web que incluye la fascinación por un rápido reconocimiento de la máquina sin las implicaciones afectivas del reconocimiento humano. Tzvetan Todorov indica en La vida en común que la esencia de lo social necesita del reconocimiento, mucho más que de la competencia o la violencia.

También necesita construir su realidad, como sucede en el sitio virtual Second Life en el cual se debe erigir una imagen dentro de un mundo artificial, pudiendo multiplicarla a través de la posibilidad de asumir distintas máscaras por medio de segundas y terceras vidas y construyendo así diversas identidades (avatar) sin persona. En suma, situaciones más o menos construidas que espectacularizan las relaciones humanas al mediatizarlas con imágenes aparte de construir territorios que reproducen el modelo capitalista a partir de la imitación de intercambios comerciales y la utilización de una moneda propia y virtual (life dollars) que, sin embargo, cotiza en la bolsa real. En suma, alteran pues la subjetividad al inaugurar nuevas apreciaciones espacio-temporales. Jacques Rancière se refiere al respecto:

(...) la generalización del espectáculo o la muerte de la imagen indican suficientemente que el terreno estético es hoy aquel en el cual prosigue una batalla que ayer tenía por objeto las promesas de la emancipación y las ilusiones y desilusiones de la historia (Rancière, 2011, p. 6).

Además, el mismo autor identifica que cierta estrechez del espacio público y de una merma en la imaginación política, producto de la caída de los grandes relatos y de la aparición de consensos, le otorgaron a las producciones artísticas y a las tecnológicas (o a sus combinaciones) una función sustitutiva. En este sentido, califica al arte como una "práctica del disenso" (Rancière, 2011, p. 120). 


\section{Distinción entre fotografía e imagen}

Muchos fotógrafos provenientes del ámbito profesional separan fotografías de imágenes. ${ }^{8} \mathrm{El}$ tratamiento de estas últimas suele ser más o menos ligera, absolutamente vinculada al presente, neutra con respecto al futuro, el que se hallará ausente como significante. Como indica Italo Calvino (p. 69): "Gran parte de esta nube de imágenes se disuelve inmediatamente, como los sueños que no dejan huellas en la memoria". ${ }^{9}$ Es por eso que se considera "fotografía" cuando proviene de una deliberada búsqueda estética y de sentido ya que en el congelamiento reflexivo reside su eficacia política. Giorgio Agamben en su libro Profanaciones establece: "La imagen fotográfica es siempre más que una imagen: es el lugar de un descarte, de una laceración sublime entre lo sensible y lo inteligible, entre la copia y la realidad, entre el recuerdo y la esperanza" (Agamben, 2009, p. 33).

Por otra parte, la indiscriminada realización de imágenes provenientes de teléfonos celulares o cámaras compactas, es decir, originadas en la esfera privada provocan también la generalización del espectáculo. Llevados a extremos, son los ejemplos de las imágenes tomadas por los mismos soldados norteamericanos (cual registros privados) en la prisión de Abu-Ghraib durante la guerra de Irak en las cuales se los podía observar realizando distintos tipos de desmanes hacia los ciudadanos nativos de ese país.

Tal vez sea oportuno recordar que ambas, fotografías e imágenes, forman parte de la ya nombrada iconósfera. Determinan pues el modo de percibir, interpretar y pensar el mundo e integran el campo de la comunicación visual. En la posmodernidad las imágenes nos construyen a nosotros: imponen modos de conducta, condicionan experiencias y puntos de vista e incluso tratan de modelar. Distinguimos hoy un nuevo modo de "fe" en la imagen fotográfica, resultado de cierta connotación de veracidad que conlleva este lenguaje y que en los últimos años se desplazó a una especie de verosimilitud ${ }^{10}$, como así también de pares dilemáticos tales como confianza y recelo, confusión y comprensión, persuasión y lucidez. Podríamos arriesgar que esto se ha producido en función de un corrimiento entre su concepción de signo (representación) para dar paso a una concepción más ligada a "ser y hacer visible" en el sentido de poder mostrar lo que sucede en distintos ámbitos, sin forcluir ninguno. Es así como las fotografías y las imágenes tienen hoy una significación flotante que navega por los lindes de los aspectos binarios mencionados anteriormente. Ambas, fotografía e imágenes se han hecho cargo en los últimos años de identificaciones primarias como la pertenencia a etnias, religiones, géneros y comunidades. Hallamos, asimismo, relatos visuales sobre los "excluidos" de los sistemas del capitalismo tardío como los desocupados, los "sin techo", etc. Otorgan pues visibilidad a comunidades y minorías postergadas mostrando problemáticas y lazos establecidos posibilitando asimismo junto a los recursos tecnológicos la aparición de comunidades virtuales. Dan cuenta, de este modo, de las micro-utopías de lo cotidiano que se han originado como tentativas de visibilización y transformación de experiencias comunitarias, barriales, etc.

No debemos soslayar la particularidad de la inmediata satisfacción de la demanda. El modo de transmisión de las imágenes y de las fotografías estará (entre otras formas más tradicionales) se ha adecuado a la unión en un solo paso del acto y del deseo. En algunos casos se tratará de un consumo y una muerte súbita de la imagen (como un espejito de cartera que refleja por 
unos minutos una realidad que sólo sirve para una confrontación instantánea pero no para el debate). Esta rapidez no contribuye a cristalizar la memoria y propicia la evanescencia y desintesifica la experiencia. Responde, muy a menudo con las exigencias del mercado mediático contemporáneo.

\section{El cuerpo como alojamiento de la identidad y la subjetividad}

Muchas imágenes contemporáneas (especialmente las publicitarias y de moda) confrontan al cuerpo y a la subjetividad y modelan identidades. El cuerpo condensa pensamientos, sueños, recuerdos, es decir, espesores de sentido. En tanto recinto del sujeto, encarna aspectos simbólicos sobre los cuales las imágenes hablan. Según David Le Breton (p.18) representa "un elemento indiscernible de un conjunto simbólico". El díptico "Big nudes" de Helmut Newton juega con la esencialidad del cuerpo tanto desnudo como vestido con el permanente aditamento en este fotógrafo del componente fetichista de los zapatos negros con altos tacos. ${ }^{11} \mathrm{La}$ imagen torna así cognoscible no solo al objeto real sino también lo vivo de ese objeto real. De este modo, en los discursos publicitarios el cuerpo es considerado un frente sobre el cual accionar por la subjetividad que transparenta. En algunos casos asistimos a una búsqueda de sumisión del cuerpo y a una exhibición sumisa del mismo. Se constituyen así, agendas y modelos discursivos que inscriben seductoramente los pares mencionados y otros más.

En algunos casos, surge un nuevo concepto sobre el ser al considerar al hombre como un conjunto de códigos de información. Modifica de este modo, la oposición binaria entre vida y muerte ya que considera la reversibilidad de la muerte a través de la posibilidad de mantener la información. En este sentido, privilegia lo inmaterial de la dualidad de Descartes (cuerpo y alma) Artistas performáticos como el australiano Sterlac, la francesa Orlan y el brasileño Eduardo Kac, entre otros, experimentan en base a esta concepción y la plasman en sus producciones en las cuales el cuerpo es factible de diversas modificaciones en un intento de integrar lo orgánico con lo inorgánico, la naturaleza y su posible modificación tecnológica.

\section{Fenómeno de hibridación}

Otro aspecto que incide en ambas esferas es el fenómeno de la hibridación contemporánea. Néstor García Canclini entiende por hibridación procesos que existían en forma separada y que se combinan para generar nuevas estructuras, objetos o prácticas (García Canclini, p. 14). La hibridación se comprende, también, en la imbricación de los distintos medios visuales con las tecnologías digitales. En este sentido, Lev Manovich ${ }^{12}$ opina que esta energía híbrida que se manifiesta es el fenómeno más interesante de la actualidad. Pone el acento asimismo en que se suscita una situación paradojal en torno a que mediante recursos tecnológicamente muy innovadores lo que se intenta realizar son imágenes tradicionalmente realistas posibles. En este sentido, se puede señalar que la imagen analógica representaba, señalaba y mostraba el mundo mientras que la imagen híbrida digital señala, muestra y representa el pensamiento.

Se observa en los hipertextos, en la red de textos que se hallan conectados que, en su diseño, aúnan cuestiones informáticas, visuales y literarias. Refieren así a lo ya definido por Gerard 
Genette en su libro Palimpsestos de $1982 .{ }^{13}$ Se hallan compuestos, además, por variables de espacio/tiempo, en virtud por ejemplo de su multidireccionalidad cual territorio que el receptor/ navegante atraviesa en un proceso que comienza y finaliza a su voluntad.

Podemos caracterizar también a los videojuegos como formas híbridas que combinan diferentes cuestiones en las que el aspecto lúdico se hace presente. Entre las cuestiones se encuentran las que responden a características posmodernas como es el simulacro. Se aprecia pues un énfasis en la construcción, fabricación, forzado y escenificación de la imagen. Los "simulacros"14 dan origen a la noción moderna de verosimilitud. La imagen ha pasado así por diferentes etapas: reflejo de la realidad profunda, enmascaramiento de esa realidad o ausencia de realidad y reflejo de un simulacro, De esta manera, las producciones ya no son juzgadas en términos de verdadero o falso, sino de credibilidad. Forman parte de este simulacro la alteración de las condiciones espacio-temporales. Instantes de credibilidad e interactividad que se asumen en la tríada imagen-interfaz-juego al igual que lo señalado en el caso de Second Life.

\section{Alquimia de lenguajes}

Con respecto a combinatorias de distintos lenguajes coadyuvados por diferentes diseños tecnológicos, en el reciente y espectacular recital brindado por Roger Waters en el estadio de River de la ciudad de Buenos Aires, se ha podido apreciar una variedad de estéticas que tratan eficazmente de responder a un imaginario global.

Un aspecto central del imaginario visual de una sociedad consiste en la estructuración del plano simbólico. Jean Paul Sastre en su libro La imaginación escribía en 1936: "La imagen es conciencia de algo." Los imaginarios inciden fuertemente en la producción de perspectivas futuras donde, además, se proyectan posibles esperanzas pero también aparecen los fantasmas que pueden ensombrecerlas; contrapuntos apreciables en los videos que se proyectan durante el recital.

Así, integrando varios lenguajes artísticos y tecnológicos, y generando por momentos verdaderas sensaciones sinestésicas, Waters en su presentación "The wall" da cuenta del panorama posmoderno y de la paulatina e histórica caída de los grandes relatos. Esto se ve representado mientras canta Goodby blue sky. En la proyección avanzan varios aviones de guerra que en determinado momento, cual bombardeo, en un color rojo sangre y en un mismo movimiento de caída desploman cruces, estrellas de David, media lunas islámicas, hoces y martillos, signos pesos como asimismo los logos identificatorios de Mercedes Benz y de Shell. Son varios los elementos constitutivos de una simbología política entre los que se encuentran los ritos, las insignias, las imágenes y las ceremonias. Las insignas, en este caso, poseen idéntica valuación entre sí, no hay referencia a lo que cada símbolo significa y son desechados por igual.

Por otro lado, llama la atención el uso que se realiza de la imagen corporativa de los i Phone, i Pad, etc. Raymond Williams denomina "tradición selectiva" a la conjunción de este tipo de elementos, entendidos como el modo en que los grupos dominantes seleccionan, preservan y muestran un bien cultural, operando sobre los procesos de definición e identificación socioculturales. Indudablemente, el branding utilizado ha logrado su cometido: el valor de marca a través de su identidad visual y, en este caso su tipografía, apela a identificaciones contemporáneas profundas y personales. 
En el recital, la amalgama de lenguajes y tecnología posee un gran valor de impacto evidenciando una vez más que las modificaciones técnicas responden a búsquedas sociales y estéticas. En este sentido, Jacques Rancière opina que los cambios estéticos preceden a los cambios técnicos y Michel Foucaut reconoce que las grandes mutaciones responden a la aparición de nuevas formas de la voluntad de verdad.

El mencionado término "impacto" significa, por un lado, el choque de un proyectil u otro objeto contra algo. Esto se ve plasmado en las imágenes de guerra que se proyectan, en el revolver que muta en objetos varios y en la permanente mención a la guerra, además del gran impacto que provoca la ruptura de la pared. Impacto se puede definir también como la huella producida por ese choque. Waters muestra abiertamente la huella que produjo en él ciertos acontecimientos sociales (guerras, desapariciones, etc.) y lo devuelve de un modo lo suficientemente impactante como para asegurarse que deja huellas en sus espectadores y que, como indica otra acepción de la palabra, produce un efecto en alguien. Espera, entonces, un efecto menos pasivo y menos recortado que la visión de todo el espectáculo a través de la pantalla de los teléfonos celulares, modalidad muy frecuente entre los receptores. Esta actual costumbre puede ser explicada a través de los comentarios del especialista en cine, Serge Daney quien, a partir de la ideología dominante, equipara ver a comprender y lo real con lo visible. Es decir, se ve y se comprende a través de la cámara.

Así, este resulta un ejemplo de arte relacional, categoría definida en los escritos de Nicolás Bourriaud, por sus procedimientos alquímicos o de collage y la relevancia de la figura del receptor. Esta estética busca crear situaciones de proximidad e intenta a través de ellas, elaborar nuevas formas de lazos sociales.

A continuación se propone vincular los dos aspectos enunciados en el título a partir de los tópicos analizados:

\section{En torno a la distribución de lo inteligible y lo sensible}

Es para nosotros absolutamente desconocido cual pueda ser la naturaleza de las cosas en sí, independientes de toda receptividad de nuestra sensibilidad (Kant, 1973, p. 192).

Esta frase de Kant define la incidencia de lo sensible en nuestra apreciación.

En cuanto a lo inteligible, René Descartes define que el hombre está compuesto por dos entes separados: por un lado el cuerpo/máquina y por otro la mente/alma humana pensante. Expresaba lo siguiente sobre sus necesidades: "Soy una cosa que piensa, una sustancia de la cual la naturaleza total o esencia consiste en pensar, y que no necesita ningún lugar o cosa material para su existencia" (Sibilia Paula, p. 86).

Por su parte, Ludwig Wittgenstein recurre a la metáfora de una malla que es construida por cada lenguaje, por cada ciencia, para dar forma a lo real, para permitir el pensamiento y la aprehensión. Sigmund Freud también interpreta la relación de este par definiendo la conciencia como parte de un sistema que recibe percepciones provenientes de un mundo exterior y sensaciones originadas en el interior. Para explicarlo recurre a la descripción del órgano de la vesícula.

La experiencia, que forma parte de este par inteligible/sensible, epistemológicamente, se encuentra ligada a la percepción y a la sensación. En la filosofía platónica se establece una diferencia entre el mundo sensible y el mundo inteligible. Francis Bacon sostenía que la experiencia es, 
no sólo el punto de partida del conocimiento, sino su fundamento último. A propósito, Kant, al igual que los pensadores empiristas, consideraba que la experiencia constituye el inicio del conocimiento. Al respecto, Giorgio Agamben determina: "La idea de una experiencia separada del conocimiento se ha vuelto para nosotros tan extraña que hemos olvidado que, hasta el nacimiento de la ciencia moderna, experiencia y ciencia tenían cada una su lugar propio" (Agamben, 2007, p. 15).

Agamben distingue la etapa de la infancia del ser humano con lo prelinguístico, planteando además que "el lenguaje es el lugar donde la experiencia debe volverse verdad." (ibid, p. 70) De este modo, a través de los diversos lenguajes (dispositivos), se establece un interjuego con las condensaciones y los desplazamientos.

Extendiendo el concepto de infancia, Agamben establece que el hombre: “(...) en tanto, que tiene infancia, en tanto que no es hablante desde siempre, escinde esa lengua una y se sitúa como aquel que, para hablar debe constituirse como sujeto del lenguaje, debe decir 'yo' " (Agamben, 2007, p. 72).

Hace referencia así al sujeto de la enunciación, a la práctica discursiva ya que la lengua existe con miras a un discurso. En la concepción "foucaultiana" de práctica discursiva, la enunciación ocupa un lugar fundacional. Michel Foucault expresa: "Analizar las positividades significa mostrar según qué reglas una práctica discursiva puede formar grupos de objetos, conjuntos de enunciaciones, juegos de conceptos, series de elecciones teóricas" (Foucault, 1969, pp. 236-237). Así, el discurso, es una instancia de análisis donde la enunciación no puede ser disociada de su enunciado. La misma es entendida, entonces, como el conjunto de condiciones presentes en la producción de un mensaje. Es decir, una enunciación que parte de la individualidad del enunciador pero, también, de su relación con la caracterización de la época tanto desde lo filosófico como desde el ámbito socio político y cultural en el que está inmerso. Emile Durkheim pronuncia al respecto: "Los hechos sociales se nos imponen."

En la actualidad las actividades estéticas dan cuenta de la evolución de los procesos productivos en su totalidad, de las contradicciones y tensiones que surgen de su práctica y de la imagen que ésta práctica proyecta de sí misma ya que enunciar es hacer presente cualquier cosa con la ayuda del lenguaje. De este modo, la enunciación constituye el universo de lo estético-artístico $y$, por tanto, se encuentra siempre presente en el interior de un enunciado. El discurso puede ser materializado a través de distintos procedimientos los que se tornan "a la vez causa y efecto del enunciado"(Filinich, 1999, p. 39).

Así, la enunciación se forma a través de una urdimbre donde la referencia a lo externo es materializada a través de una interioridad y la forma en que se va estableciendo la interacción entre ambos. Se podría aventurar aquí cierto enlace conceptual entre enunciación y "signatura" en los términos en que Agamben describe este último término. La signatura torna inteligible al signo y conforma el momento de la creación pero se manifiesta íntegramente recién en el momento de la "revelación" (op. cit. p. 60) Los enunciados al igual que las signaturas signan, caracterizan y, al mismo tiempo, orientan y determinan la interpretación de la significación de los signos. La signatura califica y especifica, pues, lo sustentado por el signo. Decir en cualquier dispositivo, en tanto práctica, no es solamente expresar un pensamiento. De este modo, la "revelación" nos devuelve a la "experiencia". Un ejemplo de esto podría ser como Marx, Freud y los herederos del pensamiento crítico, como Benjamin, consideraron lo ordinario como bello en tanto huella de lo verdadero. 
Jacques Rancière también une los términos enunciación y experiencia al establecer lazos entre estética y política. La política refiere a modos de subjetivación al recurrir a actos y formas de enunciación en un campo de experiencia. Profundiza esta idea al decir que la política consiste en introducir sujetos y objetos nuevos, en tornar visible lo que hasta el momento resultaba imperceptible para configurar así un nuevo reparto de lo sensible. ${ }^{15}$

Un gran panorama de posibilidades de enunciación se abre en la actualidad con el hipertexto según el especialista en arte medial Siegfried Zielinski de la Academia de Artes y Medios de Köln y de la Universidad de Arte de Berlín. Como estudioso de los antecedentes históricos de la relación arte/técnica y tecnología identifica un primer momento de inflexión a fines del siglo XVI, comienzos del XVII cuando aparece por ejemplo, la anamorfosis, recurso muy utilizado hoy en animación digital y que recibe el nombre de morphing. Respecto a esta distorsión visual, representada en el cuadro "Los Embajadores" de Hans Holbein, Lacan (Los cuatro conceptos fundamentales del psicoanálisis, El seminario, libro VI) sostenía

(...) todo lo que recuerda, en la perspectiva de la época, a la fatuidad de las artes y las ciencias, el secreto de este cuadro se desvela en el momento en que, alejándonos lentamente de él, poco a poco, hacia la izquierda, y después volvemos, vemos qué significa el mágico objeto flotante. Refleja nuestra propia nulidad en la figura de la cabeza de muerto. Uso, pues, de la dimensión geométrica de la visión para atrapar al sujeto, insinuación evidente del deseo que, por tanto, permanece enigmático (Lacan, 1964, p. 31).

De este modo, queda claro que la alianza arte y ciencia comienza tempranamente como recurso contenedor de un imaginario que necesita asociarlas.

Zielinski opina que, en el presente, falta poder integrar lo racional con lo sensible. En la creación multimedial se deben tomar muchas decisiones técnicas en relación a la lógica de las máquinas y sucede que la preocupación está puesta en ese desarrollo y no en el deseo de expresar lo sensible. Es por eso que concluye que lo digital le debe aún mucho a lo analógico ya que todavía no ha podido encontrar el poder de dramatización, de pasión, de sonrisas, de lágrimas, de narrativa que habita en la perspectiva analógica. De algún modo, carece de la perspectiva subjetiva-emocional, del pliegue que une pensamiento y emoción. En términos de Foucault (1982): "La emoción es el movimiento que hace que el alma actúe y se propaga espontáneamente de alma en alma."

Luego, la estética contemporánea sostiene que el arte construye espacios y relaciones que conforman visible y simbólicamente un territorio común. Los desplazamientos de las disciplinas y de los géneros dan cuenta de la redistribución de las relaciones entre el cuerpo, las imágenes, los espacios y los tiempos (presencia de temporalidades heterogéneas). La experiencia sensible se encuentra asociada a la función de la materia. No existe pues la otrora oposición entre la forma inteligente (del objeto) y la sensibilidad que el mismo despierta. De este modo, el gesto creador pertenece desde a una superficie pictórica hasta una interfaz donde arte puro, arte aplicado y arte funcional se sustentan. 


\section{Desde lo didáctico}

Por todo lo expuesto, la educación superior debe acercarse a una pedagogía de la imagen que pueda trabajar sobre los límites de credibilidad de la misma así como sobre sus niveles de impacto. A propósito, la pensadora Susan Sontag ha trabajado este tema en varios de sus textos, sobre todo en el libro Ante el dolor de los demás. Las universidades deberían aproximarse a una pedagogía que incluya interrogaciones sobre sus condiciones de producción, circulación y recepción. Es decir, que aporte un conjunto de herramientas críticas donde se obtengan los elementos para entrever por ejemplo, no sólo lo presente en una imagen, sino también lo ausente y en ese proceso lo que ella naturaliza y jerarquiza. A su vez, que pueda distinguir que no todas las imágenes visualizan la realidad de un modo transparente ya que, en algunos casos, se debe realizar un análisis sobre su opacidad. Francois Recanati sostiene que el signo posee un carácter doble: puede ser opaco y transparente, puede descubrir pero también ocultar la cosa significada, es decir, trasunta una especie de paradoja. Tal vez, para un exhaustivo estudio de la imagen, la solución de la paradoja consista en aceptar un tercer estado del signo: transparente y opaco a la vez, es decir, un signo que representa y refleja de distintos modos.

La subjetividad marca los modos de ver tal como lo indica el escritor y crítico de arte John Berger en su libro del mismo nombre. Se mira a través de la relación que establecemos con el objeto y nosotros mismos. En este sentido, la educación superior debe formar no sólo "lectores" de imágenes, sino verdaderos actores conscientes de las complejas variables que habitan en lo visual ya que contienen una significación cultural sobre las prácticas sociales. Tal como lo expresa el especialista Fernando Hernández ${ }^{16}$ :

No para hablar de lo que "se ve" en la verdad de la representación, sino para reconocer cómo cada individuo "se ve" y es colocado en prácticas de discurso, como estrategia para provocar posiciones alternativas y proyectarse en otros relatos (Hernández, 2007, p. 14).

El sociólogo y filósofo Zygmunt Bauman denomina "fetichismo de la subjetividad" a lo que subyace tras la sociedad de consumo, al no visualizar los rastros del intercambio comercial que construyen una identidad que persigue a los elementos que idealiza. Este autor concluye su libro Vida de consumo con una cita de Günther Anders, el filosófo que alertara sobre las consecuencias de la técnica y la tecnología utilizadas al servicio de los poderes concentrados con consecuencias sobre el medioambiente y la paz mundial. La misma advierte:

(...) nuestra incapacidad de controlar el ritmo de nuestra creación y de recuperar en el futuro (que nosotros llamamos 'presente') los instrumentos que se han apoderado de nosotros. (...) No es inimaginable que nosotros, fabricantes de esos productos, estemos a punto de crear un mundo al que no seremos capaces de seguirle el paso y que excederá completamente nuestra capacidad de 'comprensión', nuestra imaginación y nuestra resistencia emocional, y que a la vez trascenderá los límites de nuestra responsabilidad (Bauman, 2010, p. 201). 
Este pensamiento podría ser completado por el siguiente de Verón: "no se los difunde como proyectos utópicos del imaginario social, sino como certezas que forman parte del 'packaging." (p. 63) Por consiguiente, la educación debería hacer hincapié en asegurar la autonomía de la voluntad humana es decir, utilizar la tecnología por interés y deseo y no por el llamado "imperativo tecnológico."

Asimismo, deben considerarse dos factores que inciden sobre los fenómenos arriba descriptos ya que pertenecen a la posmodernidad. En las carreras proyectuales se torna especialmente visible la creciente estetización de la vida cotidiana. Se observan así nuevas condiciones materiales y culturales que influyen directamente sobre la sensibilidad al incorporarse en todas las dimensiones de lo social. Esta estetización implica, entonces, la incorporación simultánea de distintos medios de producción y de circulación, es decir, los elementos indispensables para que la estetización sea considerada como un valor de cambio y se convierta en capital. Como argumenta Pierre Bourdieu, se transforma en capital cultural para ser absorbido así por el imaginario social.

Jesús Martín-Barbero completa esta caracterización del siguiente modo:

La otra perspectiva que hoy cubre el diseño cultural es la de una práctica social, profesional, desarrollada a partir de las articulaciones entre varios y muy diversos "oficios": el del arquitecto, el publicista, el artista gráfico, el animador, el comunicador y el gestor. Más que de un "especialista" en el sentido actual del término, el de diseñador es un oficio globalizador y sintetizador de sensibilidades sociales, saberes humanísticos y habilidades operativas, capaz de establecer redes de diálogo entre creación artística y consumo cultural, entre lógicas económico-empresariales y dinámicas culturales, entre movimientos trasnacionales y situaciones locales (Martín-Barbero, 2002).

Todo lo hasta aquí expuesto posibilita la identificación de nuevos modelos de sensibilidad que articulan la lógica y la imaginación. Por ello, la educación superior debería ocuparse entonces de su entrecruce, del espacio liminal que actúa como un pasaje estructurado en modo indicativo para dar cabida a un espacio-tiempo en modo subjuntivo, en el cual un abanico de posibilidades de gestación creativa tenga la ocasión de emerger. ${ }^{17}$ Una pedagogía así aportaría un sistema latente de alternativas que originaría formas innovadoras.

En la medida que los docentes seamos concientes de que nuestro rol tiene una proyección social, en la medida que podamos atender no solo lo existente sino también lo emergente, se dará cabida a que el alumno pueda indagar y relacionar contenidos. En ese proceso se podrán crear narrativas que aporten fundamentalmente, sentido, sentidos "en y con" el mundo, solicitados por la subjetividad contemporánea.

En suma, resulta un desafío para el docente incorporar la iconósfera y la tecnósfera e introducir, además, un pensamiento crítico que intente liberar simbólicamente al individuo de los "guiones identitarios predeterminados" (Richard, 2006, p. 105).

De este modo, la reflexión crítica a enseñar propondrá un sujeto creativo que pueda entablar sus propias certezas e interrogaciones $y$, dentro de esas certezas e interrogaciones, logre recuperar su singularidad tanto individual como colectiva. Eliminar, de esta forma, las miradas 
apocalípticas y las hiper-integradas en torno a las nuevas formas de ver y mostrar el mundo en el ámbito educativo. Al mismo tiempo, recuperar hacia el alumnado e internamente el valor de la palabra del docente en virtud de la particular relación que existe entre la manera de decir, de hacer y de ser.

\section{Finalmente}

Lo hasta aquí examinado conforma un línea de investigación que será continuada en virtud de que la visualidad, materializada por técnicas y tecnologías, se encuentra atravesada por el sentido y la historia en tanto articula lo visible y lo decible. Además, los distintos recorridos realizados demuestran que en la actualidad subyace un cierto escenario en el que se encuentran los pliegues y los despliegues de la incertidumbre y de la nostalgia dando cuenta así del concepto contemporáneo de lo sublime planteado por Jean Francois Lyotard.

Así los diferentes actos estéticos configuran distribuciones de la experiencia que originan nuevas formas de subjetividad. Por ende, son proposiciones de una realidad contradictoria que contiene deseos irresueltos y resultan, al mismo tiempo, medios de inscripción de sentido que intervienen en las maneras de hacer y en los modos que se adoptan para su visibilidad. Por ello una superficie no es un conjunto de líneas conformadoras de un fragmento sino que es un elemento en el cual se reparte lo sensible y lo inteligible. Es entonces, desde donde se perfilan las formas sensibles y los marcos materiales del devenir.

\section{Notas}

1. Término acuñado por Nicholás Mirzoeff en la entrevista realizada por Inés Dussel para la revista Propuesta Educativa no 31 de junio 2008 en la que también menciona que este tratamiento de la palabra "visualidad" comienza a utilizarse a partir del libro Visión y visualidad del crítico de arte Hal Foster en 1988.

2. Cuyo rol en la actualidad es protagónico.

3. La autora de estas líneas realiza frecuentemente investigaciones históricas utilizando la imagen fotográfica como "dispositivo ideal para cepillar a contrapelo la historia" tal como recomendara Walter Benjamin, en acuerdo con lo que Michel Foucault menciona en su libro La Arqueología del Saber: “(...) mostrar según qué reglas una práctica discursiva puede formar grupos de objetos, conjuntos de enunciaciones, juegos de conceptos, series de elecciones teóricas”. 4. Ambos verbos son utilizados en este sentido por Deleuze, Gilles; Guattari Felix en Mil mesetas. Capitalismo y Esquizofrenia, Valencia, Ed. Pre-textos, 1996 y nuevamente por Guattari en Caosmosis, Buenos Aires, Manantial, 1996.

5. Existen varias definiciones de interfaz pero todas aluden a un dispositivo físico y/o virtual que relaciona distintos entes para su interactuación.

6. Desde Immanuel Kant en adelante se considera que la estructura espacio/tiempo es un elemento configurador de la sensibilidad.

7. A propósito, la autora de estas líneas mientras se hallaba corrigiendo las mismas, escuchó en 
la radio la noticia de la creación en 3D de una supuesta cantante pop. Entran así en juego no solo nociones de simulacro sino también de artificialidad. Cabe entonces la pregunta cual es el límite para el comienzo del exceso.

8. Los fotógrafos y estudiosos de este lenguaje, Joan Fontcuberta y Christian Caujolle, entre otros, han debatido en distintos ámbitos con respecto a esta diferenciación. Algunas de sus apreciaciones pueden encontrarse en http://ubiquitat.dialegskrtu.cat/es/quant-a/ y en la entrevista que le hiciera la revista de cultura argentina $\mathrm{N}$ a Christian Caujolle en su número del 17 de mayo de 2008.

9. Es interesante observar que el filósofo Vilém Flüsser identifica en su libro Una filosofía de la fotografía, (Madrid: Editorial Síntesis, 2002) esta especie de imágenes con el término "alucinación". 10. Los mecanismos de desplazamiento son una característica semiótica en la medida en que atañen a la producción de significado. Uno de los desplazamientos que se observa en la fotografía contemporánea es el paso de la veracidad a la verosimilitud. Si bien muchos autores sostienen que la fotografía nunca fue auténticamente real, sino que estuvo desde un principio basada en formas más o menos directas de simulacro, esto se ha agudizado en virtud de las escenificaciones de las que hoy la fotografía es objeto.

11. Helmut Newton (1920-2004) fotógrafo de modas y de desnudos nacido en Berlín. Sus fotos reflejan una diversidad de tensiones en torno al cuerpo, a la belleza, al glamour, a la sociedad. $\mathrm{Su}$ obra ha sido expuesta en numerosas instituciones y en varias publicaciones. Falleció en Los Ángeles.

12. En su libro El lenguaje de los nuevos medios ha realizado una exhaustiva investigación sobre las mencionadas mixturas.

13. Gerard Genette en su libro Palimpsestos menciona la existencia de un pasaje de un texto A (hipotexto) a uno B (hipertexto) Este último produce distintos tipos de relaciones tales como parodia, pastiche, travestismo, imitación, collage y posibilita la mezcla de diferentes géneros discursivos (Madrid: Taurus, 1982).

14. Concepto que proviene del pensador Jean Baudrillard.

15. Estos conceptos de Jacques Rancière se desprenden de los libros: El desacuerdo, Política y Filosofía, Buenos Aires: Nueva Visión, 2007, El malestar en la estética, Buenos Aires: Capital Intelectual, 2011 y El reparto de lo sensible, Santiago de Chile: Lom Ediciones, 2009.

16. Profesor de diversas áreas (Psicología, Historia de la Educación Artística, Educación de las Artes, Cultura Visual, entre otras) en el Departamento de Dibujo de la Facultad de Bellas Artes en la Universidad de Barcelona, España. Dictó una conferencia el 20 de abril del 2011 en la Casa del Bicentenario de Buenos Aires.

17. Se toma prestado el concepto de espacio liminal del antropólogo Victor Turner (19201983). Este autor desarrolla en El proceso ritual (1969) el concepto de liminalidad como una categoría de comprensión que no sólo se aplica al campo de la antropología sino que es utilizado también en el ámbito de la sociología y la psicología. 


\section{Referencias Bibliográficas}

Agamben, G. (2009). Profanaciones. Buenos Aires: Adriana Hidalgo. (2009). Signatura rerum. Buenos Aires: Adriana Hidalgo.

(2007). Infancia e historia. Buenos Aires: Adriana Hidalgo.

Bonitzer, P. (2007). El campo ciego. Ensayos sobre el realismo en el cine. Buenos Aires: Santiago Arcos.

Calvino, I. (Ed. 2007). Seis propuestas para el próximo milenio. Madrid: Ediciones Siruela.

Comolli, J. L. Cuerpos y tecnología y Máquinas de lo visible en Yoel, G. y Figliola, A. (coord.) (2010). Bordes y texturas, reflexiones sobre el número y la imagen, Universidad Nacional de General Sarmiento, Buenos Aires, Imago Mundi.

Filinich, M. I. (1999). Enunciación. Buenos Aires: Eudeba.

Fontanille, J. Semiótica del Discurso, citado por Romero, A.; Giménez, M. (sel. notas) Enunciar en Romero, A. (dir.) De Artes y Pasiones. Buenos Aires, 2005. Disponible en: www.deartesypa siones.com.ar

Foucault, M. (1992). Régimen de la verdad, La verdad y las formas jurídicas. Barcelona: Editorial Gedisa.

(1982) Prefacio del catálogo de la retrospectiva de Duane Michals en el Museo de Arte Moderno de la Ville de Paris en 1982.

García Canclini, N. (Ed. 2008). Culturas híbridas. Buenos Aires: Paidós Estado y Sociedad.

Gauthier, G. (1996). Veinte lecciones sobre la imagen y el sentido. Madrid: Cátedra.

Guasch, A. M. (2003). Los estudios visuales. Un estado de la cuestión, en Estudios Visuales \#1, Noviembre.

Hernández, F. (2007).Espigador@s de la cultura visual. Barcelona: Octaedro.

Le Breton, D. (2006). Antropología del cuerpo y modernidad, Buenos Aires: Nueva Visión.

Rancière, J. (2011). El malestar en la estética. Buenos Aires: Capital Intelectual.

(2009). El reparto de lo sensible. Santiago de Chile: Lom Ediciones.

Richard, N. (2006). Estudios Visuales y políticas de la mirada en Dussel, I.; Gutierrez, D. (comp.)

Educar la mirada. Políticas y pedagogías de la imagen. Buenos Aires: Editorial Manantial.

Sartori, G. (1998). Homo videns, la sociedad teledirigida. Madrid: Taurus.

Sibilia, P. (2009). El hombre postorgánico. Buenos Aires: Fondo de Cultura Económica.

Verón, E. (2002). Espacios Mentales. Buenos Aires: Gedisa.

Williams, R. (1980). Marxismo y literatura. Barcelona: Península.

\section{Bibliografía}

Agamben, G. (2011). Desnudez. Buenos Aires: Adriana Hidalgo

(2001). Estancias. Valencia: Pre-Textos.

Bauman, Z. (2010). Vida de consumo. Buenos Aires: Fondo de Cultura Económica.

Bonitzer, P. (2007). El campo ciego. Ensayos sobre el realismo en el cine. Buenos Aires: Santiago Arcos.

Bourriaud, N. (2009). Radicante. Buenos Aires: Adriana Hidalgo.

Estética Relacional, Buenos Aires, Adriana Hidalgo, 2008 
Cabrera, D. H. (2007). Reflexiones sobre el sin límite tecnológico en Revista Artefacto no 6.

Deleuze, G.; Guattari, F. (1996). Mil mesetas. Capitalismo y Esquizofrenia. Valencia: Ed. Pre-textos. Dussel, I.; Gutierrez, D. (comp.). (2006). Educar la mirada. Políticas y pedagogías de la imagen. Buenos Aires: Editorial Manantial.

Farina, A. (2007). Homo videns en Experiencias y propuestas en la construcción del estilo pedagógico en diseño y comunicación, XV Jornadas de reflexión académica, Facultad de Diseño y Comunicación, Universidad de Palermo. Buenos Aires.

Flusser, V. (2007). Fragmentos de Filosofía de la caja negra en revista Artefacto no 6.

González Requena, J. (2010). Lo Real, en Trama y Fondo $n^{\circ} 29,2^{\circ}$ semestre.

Guattari, F. (1996). Caosmosis. Buenos Aires: Manantial.

Gubern, R. (2004). Patologías de la imagen. Barcelona: Editorial Anagrama.

Manovich, L. (2010). El futuro de la imagen en Yoel, G. y Figliola, A. (coord.), Bordes y texturas, reflexiones sobre el número y la imagen, Universidad Nacional de General Sarmiento. Buenos Aires: Imago Mundi.

Mitchell, W. J. T. (2009). Teoría de la imagen. Madrid: Ediciones Akal.

Niedermaier, A. (2009). La fotografía: un modo de visualizar la historia, XII Jornadas Interescuelas, Universidad del Comahue, Bariloche.

Rancière, J. (2011). El destino de las imágenes. Buenos Aires: Prometeo,.

Toffler, A. (1980). La tercera ola. Barcelona: Plaza \& Janés.

Verón, E. (2002). Espacios Mentales. Buenos Aires: Gedisa.

Weibel, P. (2001). El mundo como interfaz en Revista Elementos, nº40, Diciembre-Febrero

Yoel, G. y Figliola, A, (coord.). (2010). Bordes y texturas, reflexiones sobre el número y la imagen. Universidad Nacional de General Sarmiento. Buenos Aires: Imago Mundi.

\section{Recursos Electrónicos}

Culturas, tecnicidades, comunicación. Disponible en: http://www.oei.es/cultura2/barbero.htm (consultado el 25.06.2011)

Entrevista a Siegfried Zielinski disponible en: http://hipermedia.wordpress.com/2010/10/26/ siegried-zielinski-1/ (consultado el 21.02.2012)

Entrevista a Siegfried Zielinski disponible en: http://www.vxv.com/video/5oZGHEarsvKt/image nes-del-rojas-interview-siegfried-zielinski-part-23-video-online.html (consultado el 21.02.2012)

Hernandez, F. ¿De qué hablamos cuando hablamos de cultura visual?, Disponible en: seer.ufrgs. br/educacaoerealidade/article/download/12413/7343 (consultado el 14.06.2011)

Martín-Barbero, . La globalización en clave cultural: una mirada latinoamericana, en Coloquio en Montreal (2002). Disponible en: www.er.uqam.ca/nobel/gricis/actes/bogues/Barbero.pdf (consultado el 24.06.2011)

Vazquez Rocca, A. (2004). Revista Philosophica, Pontificia Universidad Católica de Valparaíso. Disponible en: http://adolfovrocca.bligoo.com (consultado el 25.06.2011). 
Summary: The emergence of the visual and contemporary technologies apply a reflection on its impact on the constitution of subjectivity and the development of discursive practices in order to elucidate the various aspects that today are the sensitivity, thought and creativity.

Key words: didactics - intelligible - subjectivity - technology - visual.

Resumo: A emergência da visualidade e as tecnologias contemporâneas solicitam uma reflexão sobre seu impacto na constituição da subjetividade e no desenvolvimento das práticas discursivas com o fim de elucidar os distintos aspetos que, hoje, fazem à sensibilidade, o pensamento e a criatividade.

Palavras chave: didática - inteligibilidade - subjetividade - tecnologia - visualidade. 